\title{
Clasicismo y génesis disciplinar antropológica: el caso de Julio Caro Baroja
}

Aún persisten muchos enigmas historiográficos dentro de nuestra disciplina, que piden ser abordados oportunamente. Naturalmente, algunos son más importantes que otros y reclaman con más insistencia una solución, pero de nada sirve que se insista en proponer soluciones a grandes problemas si no se dan previamente las condiciones para ello. Igual que en el mundo jurídico, tampoco en el mundo académico o científico conviene plantear juicios que no se vayan a ganar, so pena de desprestigiar la posible solución propuesta: un reo no puede ser juzgado dos veces por el mismo delito, y una teoría explicativa que fracasa tiene muchos puntos de similitud con una acusación que no se prueba. Las teorías, como las amenazas, van perdiendo fuerza operativa a medida que no se confirman.

La ocasión que me brinda este homenaje corporativo a don Julio Caro Baroja es excelente para plantear un problema historiográfico tan peliagudo y correoso como el del origen fundacional de la antropología y -algo más importante aún- el de su corolario inevitable acerca de la identidad disciplinar: la elección cronológica procede inexcusablemente de una concepción determinada de la disciplina, aunque a veces no se reconozca. Queremos probar que don Julio pertenece a la tradición etnográfica y antropológica de un modo totalmente ortodoxo, a pesar de las dudas que a él mismo le han asaltado a veces de ser más historiador que antropólogo; como cuando, en reacción a las críticas de EvansPritchard a sus maestros funcionalistas y defendiéndose de su propia influencia, declaraba con aparente sinceridad en su memoria familiar Los Baroja (1972: 506-507):

no entré en su escuela o grupo porque yo he sido siempre en esencia un historiador [...] nunca he podido escribir nada sin pensar en profundidades temporales y en irregularidades, disarmonías y contradicciones. No tengo una cabeza teológica ni sociológica [...] Me cuesta mucho encontrar el orden donde sea. En Oxford había que descubrirlo con claridad meridiana: fuera religioso, fuera social...

Lo más curioso de todo es que Evans-Pritchard estaba en esos mismos años rebelándose contra sus maestros funcionalistas Radcliffe-Brown 
y Malinoswki, y afirmaba en su famosa Marett Conference de 1950 que la antropología social era una parte de las humanidades, como había enseñado antes de Radcliffe-Brown el profesor Marett, y que era más bien disciplina histórica o arte -que no natural, o propiamente científica, como pretendía el viejo maestro Durkheim, a quien seguían Malinowski y, sobre todo, Radcliffe-Brown. Y por su parte, Julio Caro acababa de publicar en 1949 un libro de historia y método etnológico en que se declaraba decididamente durkheimiano, contra su maestro Aranzadi ${ }^{~}$. Con mucha razón, se queja don Julio en este capítulo de sus memorias de los vaivenes paradigmáticos de una ciencia como la antropología social, donde los funcionalistas son vapuleados por sus discípulos luego de haber hecho ellos lo mismo con sus maestros los difusionistas, y éstos con los evolucionistas, los padres fundadores de la disciplina. Como se ve, en cierto modo, su escrúpulo disciplinar de pertenecer a esta ciencia tan tornadiza responde a un problema real de la disciplina antropológica, colocada desde su origen en el intersticio incómodo de otras ya constituidas (ciencias naturales y humanísticas en general, y en particular muchas más: como medicina, biología, derecho, filología, arqueología, historia antigua, etc.). Por ello mismo, también nos gustaría mostrar en esta ocasión oportuna que su caso no es anómalo sino que tiene una perfecta trabazón con el origen y desarrollo posterior de la disciplina, y con las dudas de una parte representativa de los antropólogos profesionales.

Adelantando mis posiciones argumentales, diré que el caso personal de don Julio como un historiador del mundo clásico, transformado en antropólogo profesional ${ }^{2}$, reproduce como en microcosmo la verdadera

1 Para una reconstrucción del cambio paradigmático de Evans-Pritchard, cf. mi trabajo en esta misma revista sobre "Antropología e Historia...", RDTP, XIIX, 2 (1994), pp. 23-24. Para la posición durkheimiana de don Julio en 1949, cf. Análisis de la cultura. Etnología-Historia- Folklore (Barcelona: C.S.I.C.), pp. 90 ss. En las pp. 111113, se dice: "Pero si admitimos la caracterización de todo hecho social de Durkheim hallamos con claridad, arrancando de un pasado remoto, la razón de las irregularidades y la técnica a seguir, por un procedimiento científico [...] y es sólo considerando también como "cosas" los hechos etnológicos e históricos como podemos dar mejor cuenta de su conexión y sus mutuas relaciones". Cf. la p. 90. para su crítica a las críticas de Durkheim por Aranzadi. Al respecto, es útil la caracterización temporal de Francisco CASTILLA en "Metodología en la obra de Julio Caro Baroja", Revista Internacional de Estudios Vascos, XXXIX, 2 (1989), pp. 272-274. Hemos de imaginarnos la reacción de don Julio, cuando solamente tres años más tarde de escribir estas frases, le demuestren en Oxford con la misma contundencia que ni Malinowski ni Durkheim deben ya ser respetados.

2 Desde el principio ha tenido Julio Caro ese doble funcionamiento de historiador del mundo antiguo y antropólogo/arqueólogo, gracias a su entrenamiento con 
historia disciplinar. Como se verá, ésta se halla íntimamente relacionada con el clasicismo renacentista, tanto en sus orígenes como a lo largo de todo su desarrollo: se trata quizá de un proceso de reconocimiento de la propia identidad, que es posibilitado a partir de la percepción estratégica de la identidad "ajena" de nuestros ancestros del antiguo Mediterráneo.

\section{ACERCA DE LOS ORÍGENES Y DE LA NATURALEZA DE LA ANTROPOLOGÍA COMO DISCIPLINA. DEBATES Y CONSECUENCIAS}

Muchas veces se han propuesto diversas soluciones acerca del verdadero período fundacional para la antropología, y el propio don Julio abordó también el tema varias veces: inclinándose, por ejemplo, en favor del período greco-latino en una de sus obras conocidas (La Aurora del pensamiento antropológico..., CSIC, 1983), o por la Ilustración kantiana en otra (Los fundamentos del pensamiento antropológico moderno, CSIC, 1985). No estamos señalando que hubiese una contradicción a un nivel directo, pues el autor lo advertía y matizaba la diferencia entre su tratamiento como idea o pensamiento - la serie sugerida desde los clásicos, o primer volumen- y luego como disciplina - la ilustrada y decimónica modernamente triunfante, tratada en el segundo volumen. Pero es cierto que se empleaba en cada caso una argumentación contraria: porque Kant no proponía ideas intencionalmente clasicistas, sino sacadas de la propia consciencia y experiencia. Para algunos de nosotros, historiadores de la antropología, planteadas así las cosas resultaba difícil dejar de sentir que ni Kant ni Hegel ni Gobineau tomaron mínimamente en cuenta para su proyecto "cosmopolita" la humanidad de los salvajes, de que les hablaban polémicamente los viajeros. Una cosa es no ocuparse de los salvajes, y otra muy distinta es negar su humanidad, del modo tan elocuente que nos transmite el testimonio de don Julio.

En ambos casos - clasicista e ilustrado- se propuso JCB una misma meta original, a saber la recuperación del tema europeo como objeto de estudio antropológico preferente para los propios europeos. Pero tampo-

Barandiarán y Aranzadi, Obermaier y Trimborn; pero su énfasis socio-antropológico se intensificó a fines de los 40, a partir de su lectura de Durkheim guiada por Ortega, y sobre todo a partir del contacto con el mundo anglosajón. Foster y Pitt-Rivers son dos antropólogos pioneros del trabajo de campo en España, enviados por sus prestigiosos maestros Kroeber y Evans-Pritchard, con quienes contacta nuestro autor en 1950-52 personalmente en N. York y Oxford. Este mismo año realiza su trabajo de campo en el Sáhara español, y su libro será reseñado en American Antbropologist como un trabajo ortodoxo, a caballo entre las tradiciones inglesa y norteamericana. 
co es del todo evidente que el conocimiento de sí en términos colectivos haya solido conducir al conocimiento de los otros: de hecho, los primitivos folkloristas eran más cosmopolitas que sus sucesores, y tanto Tylor como Machado, Carreras Artau o el propio Caro se formaron en un universo mental no regionalista, sino más bien cosmopolita. Lo que no quiere decir que no fuera usada frecuentemente como clave de nuestra historia gremial esa misma consigna socrática, del previo auto-conocimiento: Broca, por ejemplo, la empleaba como lema originario en sus Memorias de la Sociedad Antropológica, y nuestro propio Velasco la grababa públicamente en el frontis de su museo. Quizá haya sido por el prestigio y capacidad legitimadora de la filosofía griega, o por la de ciertas tradiciones médicas (nacidas a su vez en autoridades griegas como Hipócrates o Galeno), o por otras causas ligadas a la actualidad.

No puede descartarse la razón que amparaba en muchos casos esa legítima elección fundacional de Sócrates - verdadero inspirador del "Conócete a tí mismó - como patrón antropológico general, porque él justamente ha solido figurar en la historia de la filosofía como el primer indagador occidental de los estudios acerca del" hombre, por oposición a los sofistas y presocráticos, filósofos tempranos interesados supuestamente en los astros y cosas lejanas, y faltos de fe en el carácter universal y fiable del conocimiento acerca de la humanidad. Para ciertos antropólogos culturales, sin embargo, este relativismo sofista —que subraya más bien el carácter aleatorio y cambiante de los componentes culturales de una sociedad dada - quedaría más cerca de la ética antropológica moderna que el afán socrático de hallar la base común de todos los hombres y sociedades en sus propias reflexiones. Personalmente, tengo la sensación de que don Julio aplicaba en su vida cotidiana y en sus concepciones sociológicas un enfoque sofista, o al menos presocrático, más bien que socrático, y de ello es prueba elocuente el espíritu general de su memoria familiar y el propio texto de La Aurora... en su capítulo final o epílogo.

Desgraciadamente, no se trata de una discusión tan sencilla como aparenta ésta de los orígenes de la antropología, y por ello persiste aún el desacuerdo. Aún sigue siendo ambiguo nuestro criterio actual acerca de nuestra historia: particularmente en el caso peninsular, donde la historiografía se halla menos desarrollada, al compás de la propia ciencia. Aquí se da aún el caso de quienes son totalmente "continuistas", es decir, que creen firmemente que siempre hubo esa cosa hoy llamada antropología desde que el hombre es hombre: ése es seguramente el caso de los folkloristas, que concebían al pueblo mismo como autor de los contenidos etnográficos y llamaban del mismo modo a este contenido y a la disciplina (folklore). Entre nosotros, incluso desde hace tiempo, algún ai- 
rado profesor de filosofía defiende que la antropología no ha demostrado aún su cientificidad genuina, tomando su pretensión generalizadora y cosmopolita como una herencia, o más bien una suplantación, respecto de la filosofía. Tómese esta "boutade" como compensación conceptual, o incluso como protesta gremial, contra otros filósofos contemporáneos que piensan sinceramente que ha concluido la función original de la filosofía de anidar todos los conocimientos, y que actualmente su misión más bien sería tomar prestado de diferentes disciplinas todo de lo que tenga necesidad: esa propuesta generosa se hizo entre nosotros por Manuel Sacristán, y recientemente es practicada abiertamente por Habermas y sus discípulos, después de haberla puesto en circulación el propio Ortega.

Y naturalmente, si nos declaramos "discontinuistas" y no creemos que hubo siempre antropología, hay luego todos los gustos para elegir un período fundacional específico entre una gama amplia de precursores: los griegos y romanos, los viajeros medievales, los humanistas, los descubridores del Nuevo Mundo, los viajeros del XVII al Cercano Oriente y Asia, los posteriores del Océano Pacífico en el xviII o del interior de África en el XIX, los ilustrados, los románticos, los evolucionistas, etc. Algunos son todavía más rígidos y esperan a la llegada del funcionalismo y los trabajos de campo de Malinowski, como el propio Adam Kuper muestra en una excelente monografía ${ }^{3}$.

Ahora bien, realmente esta decisión no suele ser siempre producto de una argumentación racional en todos los manuales históricos; ni siquiera en los ensayos breves, donde parecería más fácil la argumentación. Al contrario, es frecuente ver una cierta indiferencia respecto al período fundacional, o creer resuelta la duda de partida con el recurso a razonamientos de lo más peregrino (la amplitud mayor o menor de conocimientos del autor y época, la idoneidad disciplinar e importancia del padre fundador en la actualidad, el inicio de la profesión científica en general a mediados del XIX, etc.). Haddon y Penniman acudieron a los filósofos griegos y a un listado inmenso de nombres y obras para llenar el vacío del pasado; después, Lowie y Marvin Harris eligieron a los ilustrados europeos - de tradición alemana o francesa, respectivamente- que les parecieron tenían suficiente información y una cierta sofisticación teórica; por su parte, los franceses Mercier y Poirier prefirieron a los viajeros del Renacimiento, con abundancia de nombres franceses, precedidos de viajeros greco-romanos y chinos; Voget, finalmente, se refiere a todos a la vez, desde los clásicos a nuestros contemporáneos, pero señalando la mayor

3 Antropología y antropólogos. La escuela británica, 1922-1972 (Barcelona: Editorial Anagrama, 1973). Original de 1973, como Penguin Books. 
pertinencia de los filósofos ilustrados para ser considerados padres fundadores, etc., etc. Incluso la especialista Regna Darnell, en su conocida antología de textos historiográficos de 1974, recoge con total indiferencia versiones para todos los gustos (a favor de los clásicos, del Renacimiento y los viajeros del Descubrimiento, y del s. XIX), pensando que no merece la pena sofisticar la búsqueda demasiado (1974: 11). Llega incluso a recoger la tesis continuista, cuando afirma que "la antropología puede considerarse un universal de la cultura humana [porque] todo humano puede tener opiniones sobre la ciencia del hombren. Al respecto, existe una crítica severa del profesor Josep Ramon Llobera en 1980 a este tipo de criterios temporales tan laxos:

Uno se puede preguntar qué ha sucedido con la Ilustración [...] De hecho, lo que pasa es que Darnell agrupa en la misma categoría a los soldados de fortuna españoles, a los viajeros de todo tipo y a los "philosophes" de la Ilustración [...] Yo me pregunto hasta qué punto [...] el uso indiscriminado de precursores [...] puede ilustrarnos sobre la antropología como ciencia [o más bien] muestran cuán ciega puede ser una historia cuando carece de una guía epistemológica ${ }^{4}$.

Contra lo que dice Llobera, Darnell era consciente del peso específico de los filósofos ilustrados en la configuración disciplinar, y valora los informes de viajeros más por el uso dado entre tales filósofos que por sí mismos. Pero, aunque luego veremos la utilidad particular de la recolección de ensayos ofrecida por Darnell, es cierto que ella misma se mantiene indiferente al problema de la demarcación temporal de la disciplina. El problema no se reduce en realidad a un criterio cronológico, o de precursores, que admitiría a fin de cuentas una solución aleatoria y poco comprometida: nada se perdería con remontar más atrás el período fundacional, con tal de incluir en nuestro patrimonio intelectual algunas

4 J. J. Llobera, "Algunos problemas epistemológicos de la historia de la antropologían, Actas del Primer Congreso Español de Antropología (Barcelona: Universidad de Barcelona, 1980), II, p. 80. Este mismo trabajo ampliado, original de 1976, se incluyó como introducción a su Hacia una historia de las Ciencias Sociales (Barcelona: Anagrama, 1980), p. 59. Es curioso que a los soldados españoles de fortuna los convierta ahora en "mercenarios", sacrificando en aras de la eficacia grotesca la enorme variedad de escritores de Indias, compuesta principalmente por religiosos como las Casas, Sahagún o el P. Acosta, y por funcionarios como Fernández de Oviedo, Alonso de Zorita o Polo de Ondegardo; todos ellos autores de excelentes informes de gran valor etnográfico, usados por la Administración de su tiempo y por los filósofos como Voltaire, Montesquieu o W. Ferguson. R. DARNELL, Readings in bistory of antbropology (N. York: Harper and Row, 1974). Discípula lejana de G. W. Stocking, es autora de un excelente informe para la revista Annual Reviews in Antbropology (1977) sobre la situación de los estudios de historia de la antropología. 
autoridades $\mathrm{u}$ obras de interés universal. Probablemente habría entonces solamente algunos conflictos de tipo regional, sobre qué autoridades antiguas incluir y sobre el porcentaje de "precursores" de una u otra procedencia nacional. Es evidente que cada país preferiría poner más fundadores propios que ajenos, pero aún así siempre podríamos llegar al acuerdo de incluir a todos, o de seleccionar cada país a los suyos.

El problema verdadero se plantea cuando la selección de ese período fundacional conlleva necesariamente una definición de la disciplina, y luego un detenido análisis del proceso por el cual esas personas y obras son realmente influyentes en la posteridad: ahí no son tan conciliables las posiciones. No es lo mismo seleccionar casos de precursores aislados y prestigiosos que tener que razonarlos en cada caso particular, y luego conectarlos entre sí y con la posteridad. En mi modesta opinión, no hay muchos casos de historias disciplinares en que la elección del período fundacional vaya acompañada adecuadamente de la exposición del criterio científico y disciplinar en que se basa, y de la correspondiente investigación acerca de la posterior influencia real de los precursores elegidos. Respecto al criterio científico para elegir como fundadores a los pensadores greco-latinos y a la ilustración alemana presidida por Kant, hay al menos en don Julio la clara pretensión de emplear uno que sea coherente con la definición que hace de la disciplina en Europa, como un conocimiento de la propia sociedad europea. Ya lo dijo Carmen Ortiz:

El influjo de Kant [...] debe entenderse [...] como una coincidencia real entre el presupuesto básico de la Antropología de Kant y el propio proyecto carobarojiano: la antropología como estudio que parte del conocimiento interior y no de la confrontación o comparación. Así, pues, el origen de la antropología como producto de la realidad colonial no es valorado. La tradición del pensamiento antropológico está en aquellos filósofos (griegos o del siglo XviI) que, desde sí mismos, desde su propia realidad circundante, se preguntan por la esencia de los caracteres y comportamientos humanos 5 .

Eso no significa que don Julio se haya inhibido siempre de la antropología europea que se ocupa de los pueblos primitivos, tanto en el caso europeo como en el español. En su propio texto de 1985, en que elige al patrocinio kantiano para inaugurar la historia moderna de la antropología, se refiere todo el rato a una versión absolutamente tradicional de la antropología, como estudio de primitivos, con solamente dos o tres capítulos finales que pudieran considerarse relativamente kantianos, es decir,

5 «Las historias de la antropología. Homenaje a JCB coordinado por A. Carreira y recogido en Cuadernos Hispanoamericanos, núm. 533-534 (1994), pp. 55-67; p. 61. 
de estudio europeo de los europeos (Antropología y sociología, El movimiento folklórico, y La antropología criminal). En realidad, es general en don Julio un planteamiento ortodoxo de la antropología en sus estudios históricos. Sin afán de exhaustividad, podemos referirnos a dos importantes escritos suyos de tipo histórico en que se recogen tales estudios sobre pueblos no europeos: me refiero al texto más doctrinal de los salidos de su pluma, el Análisis de la cultura (Etnología-Historia-Folklore) (Barcelona, C.S.I.C., 1949) y a una conferencia de clausura de los cursos de verano, Una imagen del mundo perdida (Santander, Univ. Internac. Menéndez y Pelayo, 1979). El primero de ellos es, además de una explicación de los métodos de estudio antropológico y folklórico en Europa, una historia disciplinar en que se entona un canto excepcional de apoyo al método durkheimiano, y donde se pretende dotar de teoría antropológica, sacada del estudio de los pueblos primitivos, al campo del folklore dedicado a los pueblos europeos:

Hace tiempo [...] ya tenía pensado que sería conveniente reunir algo de teoría para uso de los folkloristas de dentro con un criterio muy personal [...] en que [se] aspira a dar una visión del conjunto de los caracteres de todos los pueblos de la tierra [...] no es sólo en España donde los estudios folklóricos que se usan como arsenal para las descripciones son inconexos y raros [...] si no es en algunas naciones del Norte, como Suecia [...] Muchos hombres de ciudad, en nuestros días [...] han visto el mundo que les rodea con ojos cansados, añorando los tiempos en que la "intuición", "el impulso vitaln, etc. dominaban a la razón [...] al encontrarse en medio de sociedades y pueblos de Africa, de Asia y Oceanía, hallaban en ellos mucho que aprender e imitar [...] el hombre común europeo no está tan saturado de cultura como ellos creían (1949: 8-9).

Como se ve, asoma claramente el afán general de dotar al estudio del hombre europeo de la misma variedad y legitimidad antropológica que a los sujetos de estudio tradicionales de la antropología, los pueblos de África, Asia y Oceanía (obsérvese ya una constante de don Julio, la ausencia de toda referencia americanista). Pero se asume también en este texto que la antropología es una disciplina del siglo XIX, y está construida en los países del norte sobre la materia informativa exótica, no europea:

La Etnología (hoy entroncada con la Historia) no es, sin embargo, hija de ella, sino de ciertas observaciones e hipótesis de tipo estrictamente filosófico, de otras creadas por los naturalistas y de un conocimiento mayor de la tierra que el que se tenía antes de la Edad contemporánea. La Etnología es un producto genuino del siglo XIX. Eso no quiere decir que en épocas anteriores no se hicieran observaciones etnológicas por los geógrafos, los viajeros, historiadores, naturalistas y filósofos. Fue justamente la insistencia en tales observaciones lo que condujo a su creación, y lo que ha producido ciertos trastornos teóricos después (1949: 17). 
Sigue a continuación un esfuerzo por valorizar las contribuciones clásicas, medievales, renacentistas e ilustradas, en que - por una vez, que yo conozca- menciona algunas de las crónicas de Indias (Sahagún y Ávila) resaltadas por los antropólogos extranjeros, uno de ellos su profesor (Schmidt y Trimborn); sólo que para destacar su falta de valoración coetánea y su consecuente carácter inédito:

Causa asombro pensar con qué rigor llevaron a cabo autores semejantes sus averiguaciones y descripciones. Pero no menos sorpresa produce a primera vista el hecho de que sus obras no fueran valorizadas hasta época moderna. La razón está, sin embargo, en la falta de elementos con que el posible lector se hallaba ante aquélla. Por eso permanecieron inéditas muchas veces, como las de los dos autores que nos sirven de ejemplo (ibid., 18).

Aparte de homenajes ocasionales a personajes de su propio entorno (Aranzadi, Barandiarán, Gómez Moreno, etc.), don Julio no escribió nunca una historia de la etnología española, aunque yo le he oído en los 80 -febrero a marzo del 83 - un curso al respecto, dictado en el Departamento de Antropología Americana de la Complutense: en él dedicó especialmente su atención a los estudiosos ilustrados (Feijoo, Jovellanos, Sarmiento, P. Isla) y del s. XIX (Españoles pintados por sí mismos, Semanario Pintoresco, Castellanos, Bécquer, Machado, Milá, y los médicos y juristas) sobre España, tratando muy de pasada los informes americanistas como "precursores" (Las Casas, Sahagún, Cobo y Acosta). Creo que no se ha publicado, como sí lo hizo con la conferencia de 1979 en la Menéndez Pelayo dedicada a los viajes españoles por Oriente, por el mundo islámico y por los Países Bajos durante los siglos XVI y XVII. Después de un repaso a la bibliografía histórico-antropológica sobre el tema, se propone explorar algunas bibliografías ("bibliotecas") españolas de la época, como la de Nicolás Antonio y, sobre todo, la del sevillano Antonio León Pinelo. Es curioso que use su voluminosa Biblioteca oriental y occidental... (Madrid, 1629 y ampliación de 1737-38) solamente para las Indias orientales y no para las occidentales, habiendo sido el autor funcionario en Perú y luego Cronista de Indias - naturalmente americanas-, y siendo mucho más cuantiosa y valiosa la producción española en América que en Asia, África y Oceanía. Por cierto, que el P. Acosta - mencionado como único autor español por la Historia de la antropología de Haddon (Caro, 1949, p. 88-89), y conocido internacionalmente por sus informes americanoses tratado en esta conferencia solamente por su alusión a chinos y japoneses como pueblos más civilizados que los mejicanos y peruanos, en uno de los capítulos dedicado a la China (VIII). Toda la alusión que merecen los centenares de escritos españoles publicados sobre las Indias occiden- 
tales es ésta: «dejemos a un lado el contenido del tomo de [...] la obra de León Pinelo referente a bibliografía americana, que es el segundo, en que se recoge también una vasta bibliografía cosmográfica y náutica" (1979: 51). No he sido capaz de encontrar una explicación a esta elusión americana, que parece sistemática, en una obra que trata de recordar la imagen del mundo creada por los españoles durante los siglos de oro ${ }^{6}$.

En todo caso no era una tarea historiográfica tan fácil la llevada a cabo por don Julio a comienzos de los 80, en estos tres libros citados (1979, 1983 y 1985), pues no conozco muchos casos más en castellano de repaso historiográfico general como el suyo (posiblemente con la excepción del texto americanista de Manuel Marzal, elaborado en parte como alumno de Ángel Palerm, que elaboró otra obra histórica equivalente, aunque ofrecida en forma de antología). Sobran razones en general para hacer elecciones parciales en una historia global, y es debido a que cada autor está inevitablemente limitado por su propia experiencia y por sus concepciones disciplinares. Solamente queda luego un problema, el de lograr o no una mínima coherencia entre los períodos históricos elegidos y las concepciones de la disciplina en que se funda cada autor, recurso lógico no siempre respetado tan escrupulosamente como en Julio Caro. Véase cómo lo intentaba en 1949 (pp. 17-18) para basar su historia posterior de una antropología exoticista, su primera versión:

6 En parte, se puede explicar por la mayor familiaridad del lector español con esta bibliografía, ya muy tratada nacional e internacionalmente, frente a las otras imágenes hispanas sobre el Cercano o Lejano Oriente, sobre el mundo islámico o sobre el norte de Europa. Por eso le llama "Una imagen del mundo perdida". En todo caso, es posible también que el lado grandilocuente con que se ha defendido por algunos americanistas españoles de postguerra la participación española en la colonización americana haya desanimado a un autor como JCB, que siempre eludió este ambiente ideológico hispanista, antes y después del 36. En su memoria familiar Los Baroja (Madrid: Taurus, 1972, varias reimpresiones y reedición en 1978) no ha dedicado ni una página a este asunto, que tan pertinente es a la generación del 98: si algo habla de "hispanismo" es para mantener sus distancias con un mundo de "ensayistas" que inventan y exageran hasta la saciedad un mundo tópico. De su viaje al Sáhara, se preocupa también en esta ocasión en justificar la identidad intelectual de los africanistas españoles iniciales, huyendo de todo espíritu colonial y afirmando su interés claramente profesional (no parece haberlo entendido así todo el mundo, incluido alguno de los historiadores catalanes que han escrito recientemente en uno de sus homenajes necrológicos). Es posible finalmente que tampoco la etnología americana le haya interesado particularmente, como reconocía con toda crudeza: «a mí los indios de América nunca han llegado a desvelarme. He tenido más curiosidad por los negros y por los pueblos de Oriente (1972: 494, y 1978: 467). Él mismo lo vio como un obstáculo en su trabajo de colaboración con Foster y la Smithsonian, cuando lo refiere en su memoria. 
Un espíritu crítico, en cuanto sale de su tierra natal a otras extrañas, lo primero que hace es apreciar las diferencias que entre ellas existen y comparar las analogías. En tan sencilla labor se funda la Etnología [...] Pues bien, en la Edad antigua (concretamente entre los pueblos clásicos), en la Edad media y en la moderna ha habido observadores sencillos de las diversidades y analogías étnicas, y teorías que pretendían dar razón de lo observado. Digamos primero algo de los observadores, para luego hablar de las teorías [...] ¿Quién podrá dudar de que las observaciones de Heródoto sobre los egipcios o los persas contemporáneos suyos, las de Jenofonte sobre los pueblos del Asia anterior y menor, las de Polibio y César sobre los galos y celtas no son del tipo simple [...]?

\section{ACERCA DEL VALOR ANTROPOLÓGICO DE LA TRADICION CLÁSICA MISMA}

Su posición en 1949, como se ve, parece respetar el dintel disciplinar del s. XIX, aunque no deja de referirse a los tiempos clásicos en franca rebeldía contra la tiranía temporal del mundo contemporáneo, por reclamar para sí el monopolio de la ciencia antropológica. En su conferencia de 1979, dedicada a las observaciones y explicaciones hispanas de los siglos XVI-XVII acerca del mundo exterior, vuelve a detenerse en los precedentes clásicos:

[...] si tuviéramos reunidas de modo sistemático y orgánico sus observaciones [españolas del siglo de orol, obtendríamos una imagen del Mundo muy peculiar y digna de tenerse en cuenta en aquella serie que podría empezar con las imágenes del mundo construidas por los primeros viajeros e historiadores griegos [...] y que habría de llegar a nuestros días, pasando por las propias de los antropólogos del siglo XIX, los filósofos del xVIII, los humanistas del Renacimiento italiano o germánico y otra gentes anteriores, más o menos famosas (Nota 3: Las historias de la Antropología y de la Etnología son muy sumarias en este orden y como si estuvieran aplastadas por los efectos de las discusiones y teorías del siglo XIX. Todo lo anterior lo consideran como puros antecedentes) (1979: 10).

Naturalmente es en la monografía de 1983 donde se detiene en los precedentes clásicos, y no se conforma con tratar la filosofía antropológica clásica al nivel de puro precedente intelectual:

Así, pues, la primera consecuencia que se puede extraer de este libro es la siguiente [...] parece claro que es entre los siglos $\mathrm{vI}$ y $\mathrm{v}$ antes de J. C. cuando se formulan las teorías principales y cuando se plantean las investigaciones antropológicas en forma racional. Después hay reacciones, no siempre positivas, ampliaciones del conocimiento de los pueblos en extensión y a veces retrocesos causados por espíritus fabuladores. Pero, en suma, los griegos crearon un cuerpo o sistema de pensamientos antropológicos que, de modo más o menos consciente, ha pesado sobre el pensamiento de pueblos posteriores, con perdón de los 
que creen que no se vislumbró qué cosa fuese la Antropología hasta el Renacimiento o los que empiezan su historia mucho después: en el siglo xviII. Porque incluso, a veces, los que se han considerado adelantos de la ciencia no son más que banalizaciones o trivializaciones, o incluso observaciones dictadas por una moda o reacción politica contra esto o aquello (1983: 223).

Como se ve, don Julio se expresa con mucha rotundidad a la hora de defender los orígenes clasicistas de la teoría antropológica, si bien en sus manuales de 1979 y 1985 reconoce con fair play la naturaleza contemporánea del carácter profesional de la disciplina. No es fácil poder combinar la verdadera antigüedad de las ideas que nutren la disciplina, e incluso el método y el contexto social, con la modernidad del nombre y del oficio que la caracteriza actualmente. Es evidente la necesidad de refinar el planteamiento, definiendo mejor la disciplina y probando la existencia continua y dominante de una práctica disciplinar, para poder distinguir taxativamente entre disciplina y profesión. Personalmente, el autor que he visto más preocupado por una coherencia sistemática entre el período fundacional propuesto y el criterio de definición disciplinar ha sido John H. Rowe (1965), cuyo texto recogió oportunamente R. Darnell en 1974 , y ha sido ya otras veces recogido y utilizado ${ }^{7}$. Lo que quiero señalar ahora solamente es el modo ejemplar en que iniciaba y concluía su conocido ensayo, cuando defendía los 'cimientos renacentistas' de la antropología:

El punto de vista comparativo de la antropología descansa en el reconocimiento de que hay diferencias físicas y culturales entre las poblaciones humanas, que deben tomarse en cuenta en todo intento de generalizar acerca del hombre. Es este reconocimiento antropológico de la importancia científica de tales diferencias lo que le distingue primariamente de otras disciplinas concernidas por el hombre y la conducta humana. La historia de tal idea es por ello una parte im-

7 "The Renaissance Foundations of Anthropology". American Antbropologist, 67 (1965), pp. 1-19. Personalmente me ha sido muy útil este trabajo en el desarrollo de mi propia investigación sobre las crónicas de Indias, desde mi tesis doctoral en 1975. Literalmente, me topé con él leyendo el librito de John H. Elliott, El Viejo y el Nuevo Mundo, 1492-1650 (Madrid: Alianza, 1972; orig. 1970, Cambridge U. P.), que le agradecía reiteradamente sus ideas: tal libro de Elliott, un ciclo de conferencias en Irlanda sobre un tema ajeno a su especialidad - y por ello, lleno de útiles referencias bibliográficas-, ha sido tan influyente para los lectores americanistas como sus trabajos hispánicos en el ámbito europeo. Desde entonces he atendido especialmente el lado intelectual de las crónicas de Indias más que su información etnográfica, y también ha determinado algo mi dedicación a la historia de la ciencia más que a la etnohistoria americana. Además, gracias a esta orientación, he emprendido luego estudios histórico-científicos sobre el Renacimiento, y en particular sobre la aportación del P. Acosta y la Compañía de Jesús. 
portante de la historia de la antropología (Nota 1... Mi argumento, inspirado por Momigliano, de que no hubo ninguna tradición continuada de antropología en la antigüedad clásica, pretende contestar la opinión común entre antropólogos interesados en su historia de que ésta se inicia con Heródoto, y desde entonces persiste de modo más o menos continuado...).

La tesis de este ensayo es que la tradición antropológica de interés por las diferencias humanas tuvo su inicio en el Renacimiento italiano de los siglos XIV y XV, específicamente en la arqueología renacentista. Las primeras diferencias que se reconocieron como significativas para el entendimiento general del hombre fueron las culturales y lingüísticas entre la antigüedad clásica y el presente. Solamente después de que se hubiese establecido una perspectiva arqueológica es cuando el interés por las diferencias se amplió a los contrastes contemporáneos. Los estudios renacentistas de la antigüedad clásica no sólo estimularon un interés general por las diferencias entre los hombres, sino que proveyeron también de modelos para describirlas. Cuando surgió el problema de describir las culturas contemporáneas no europeas, se dispuso como precedente de los estudios renacentistas sobre las costumbres e instituciones romanas. Similarmente, las gramáticas y diccionarios del latín y griego clásicos devinieron modélicos para describir los lenguajes de todas las partes del mundo, y el estudio de los antiguos monumentos de Italia y Grecia serían la base de todo reportaje arqueológico posterior. Los comienzos de la antropología física se demoraron, porque se dispuso de pocos precedentes de este tipo con la antigüedad clásica.

En orden a demostrar el origen renacentista del punto de vista comparativo de la Antropología es necesario probar dos cosas: primero, que no hubo ninguna tradición antropológica continua de estudios comparados que se remontasen a la antigüedad clásica desde la Edad Media; y en segundo lugar, que el interés por las diferencias de costumbres, lenguajes y antigüedades locales -característico de algunos escritores del período de los viajes de descubrimiento- estaba relacionado con un cambio fundamental en las actitudes de aquellos hombres hacia la antigüedad clásica, propio del Renacimiento italiano.

[...] La perspectiva antropológica debe mucho a la experiencia europea en los grandes viajes de descubrimiento, pero no se originó en la observación de las diferencias contemporáneas. Los viajeros vieron solamente lo que estaban preparados a ver, y sus ojos ya habían sido primeramente abiertos por el estudio de la antigüedad clásica, en un marco que les permitía contrastar con su propio tiempo [...].

El entusiasmo del Renacimiento por la antigüedad clásica tuvo el efecto secundario de romper la concha del prejuicio etnocéntrico que tradicionalmente había aislado a los hombres europeos. Si los griegos y romanos fueron tan grandes maestros, nunca igualados luego, era ridículo para cualquier pueblo moderno reclamar una excelencia exclusiva (1965: 1 y 14, traducción mía).

El interés del planteamiento me excusa en esta oportunidad de la amplitud excesiva de la cita. Lo que se contiene luego en este ensayo breve, pero magistral, es exactamente lo prometido: una muestra previa de los prejuicios clásicos y medievales generalizados sobre el mundo ajeno - con excepción destacada de Heródoto, Megástenes, Marco Polo y Carpini/Rubroek, todos los cuales eran tenidos por "fabulosos" en su tiempo, 
según probó Momigliano- y la posterior aclamación de estas fuentes por parte de algunos eruditos modernos de Italia (Petrarca, Boccaccio, Flavio, Pizzicoli, Valla), que explicase de alguna manera la excepcionalidad del interés etnográfico de Pedro Mártir y los demás humanistas europeos por las novedades antropológicas del Nuevo Mundo, o de Alvise Cadamosto por África. A su vez, y como corolario lógico, que justificase la masiva y continuada bibliografía dedicada al mundo europeo y no europeo desde entonces hasta nuestros días, pero ya con ojos antropológicos: es decir, describiendo y explicando razonablemente las diferencias físicas y culturales entre las muchas sociedades conocidas.

Personalmente he hallado este ensayo muy útil para estudiar la producción etnográfica española en América, especialmente la variada serie de escritos religiosos y laicos acometidos por españoles del s. XVI sobre los pueblos americanos de Mesoamérica y los Andes, que ha permitido a muchos antropólogos norteamericanos considerarlos fundadores de la antropología occidental (Sahagún, Las Casas o Acosta principalmente). A ello dediqué mi tesis doctoral de 1975, a confirmar la valoración de las famosas "crónicas de Indias" en la bibliografía histórico-antropológica, en la que el trabajo de Rowe representaba uno de los ensayos más respetables en este sentido, independientemente de que en él se ocupase solamente de sus "precedentes" italianos ${ }^{8}$. Lo que hallo más valioso del ensayo no es el período de estudio elegido como etapa fundacional, ni los nombres concretos y la nacionalidad de los modelos - cosas que me parecen relativamente coyunturales, y sujetas a revisión-, sino más bien el procedimiento de concebir la historia de una disciplina como campo de ensayo de una definición disciplinar, así como respecto del proceso de conocimiento particular que le ha conducido a constituirse como disciplina.

A partir de este breve ensayo estamos obligados a proceder en nuestra historiografía de modo que se pueda explicar razonablemente la adscripción legítima de los autores del pasado a la disciplina y, en particu-

8 En realidad, el profesor Rowe escribió este ensayo como 'prólogo' a otro trabajo posterior sobre las "crónicas de Indias" del siglo XVI, en que la obra del P. Acosta era vista como culminación de la información etnográfica más selecta recogida hasta entonces, y como precedente más antiguo de las "antropologías" evolucionistas del s. XIX, consideradas por Rowe fundacionales de la disciplina moderna pero llenas de prejuicios culturales y de desviaciones europeizantes. El profesor Rowe es un prestigioso arqueólogo incaísta de la Univ. de California en Berkeley, cuyos conocimientos sobre los métodos antropológicos y sobre las fuentes etnohistóricas del mundo andino son muy considerables. Cf. "Ethnography and Ethnology in the Sixteenth Century", Kroeber Anthropological Society Papers, 30, pp. 1-19 (Berkeley, 1964), y sixteenth and Seventeenth Century Grammars", en Dell HymEs (ed.), Studies in the History of Linguistics. Traditions and Paradigms (London and Bloomington: Indiana U. P., 1974). 
lar, que se pueda valorar en términos sistemáticos la influencia positiva del clasicismo sobre el desarrollo disciplinar de la antropología. Como esa valoración ha sido propuesta por don Julio reiteradamente, y él mismo ha dedicado su esfuerzo temprano a la historia antigua, y luego siempre ha conservado un lazo de referencia y óptica clasicista - como veremos más tarde-, creemos llegada la ocasión de proponer de un modo más detenido la valoración del clasicismo en la antropología: primero en términos generales, y luego en el caso particular de don Julio.

No merece ahora la pena subrayar tanto los contrastes entre el modelo de Rowe y el de don Julio como sus coincidencias, que nos parecen más importantes y pertinentes. Es verdad que Caro Baroja valora especialmente el legado clásico más que el clasicista del Renacimiento o el de las "crónicas de Indias", y que se fija con más interés en el contenido intelectual que en la función de previo "extrañamiento" (como le llama Lévi-Strauss) que produce el legado clásico sobre el hombre moderno. Pero posiblemente, el contraste entre Rowe y Caro es más de forma que de fondo: ya que ambos están convencidos del efecto "desencadenante" intelectualmente del legado clásico en el período moderno, y lo están porque ambos son bien expertos en el conocimiento directo del mundo clásico $^{9}$. Ambos son eruditos, a contracorriente de las modas científicas, y tienen un mundo propio que defienden con terquedad. Rowe es experto en "crónicas de Indias" como Caro en las greco-romanas, porque ambas son imprescindibles para "reconstruir" el mundo cultural del Perú antiguo y la España antigua, sus dos campos de estudio, en que sobresalen al mismo tiempo que en su interés leal y persistente por la conservación de esa herencia en el presente.

Tratemos, pues, de dar unas pinceladas sobre los precedentes históricos que tienen ellos dos como antropólogos "genuinos", aunque pertenecientes al campo de la historia antigua, y modelados intelectualmente por la cultura greco-latina. En mi opinión, sus dos vidas y los precedentes que encontremos probarán mejor sus postulados, aparentemente contrapuestos, que cualquier argumento lógico en abstracto.

9 El padre de Rowe era arqueólogo del mundo clásico greco-romano, y él mismo aplica esquemas de la arqueología clásica al mundo incaico y se opone de modo sistemático a las modas tecnológicas que visitan de tiempo en tiempo el mundo de la arqueología americana: radio carbono, termoluminiscencia, dendrocronología, etc. 


\section{ACERCA DEL PESO CLASICISTA EN LA ANTROPOLOGÍA MODERNA Y CONTEMPORÁNEA}

Ya hemos visto el valor general concedido a la contribución clasicista en el origen de la disciplina antropológica, según la historiografía de don Julio y de algunos manuales internacionales. Ahora me gustaría poner esquemáticamente algún ejemplo clasicista de este período fundacional, para luego poder mostrar que la razón intelectual de su papel disciplinarmente desencadenante se ha cumplido de modo más general, y a lo largo de los demás períodos sucesivos, incluso hasta la actualidad. Si es cierto que el conocimiento y aprecio de la cultura clásica permite al hombre moderno educado en esta tradición romper los lazos etnocéntricos, y también le provee de un modelo descriptivo e interpretativo que aplicar a las otras culturas, contemporáneas o pasadas, entonces el efecto positivo no ha debido restringirse al período fundacional del Renacimiento. Naturalmente, luego del período primero, este papel ha podido ser llevado a cabo del mismo modo por otras tradiciones "mediadoras", como por ejemplo las culturas orientales u oceánicas. Así es como lo ha concebido Lévi-Strauss, en un somero repaso histórico a su disciplina realizado en 1956, con motivo de una encuesta sobre la vigencia de los estudios clásicos en Francia:

Se reconocía (con el Renacimiento) que ninguna civilización puede pensarse a sí misma, si no dispone de algunas otras que le sirvan de término de comparación. El Renacimiento ha reencontrado en la literatura antigua nociones y métodos olvidados; y algo más aún, el medio de poner su propia cultura en perspectiva, confrontando las concepciones contemporáneas con las de otros tiempos y otros lugares.

Los que critican el aprendizaje clásico incurren en un engaño [...]. Como los profesores de secundaria saben bien, a través de la lengua y los textos de griego y latín se inicia el alumno a un método intelectual parecido al de la etnografía, que yo llamaría con gusto la técnica del extrañamiento.

[...] En los siglos XVIII y XIX, el humanismo amplía su horizonte con el progreso de la exploración geográfica [...] donde se inscriben en el cuadro la China y la India [...] Al interesarse hoy por las últimas civilizaciones que rescatar del desprecio - la de las sociedades primitivas- la Etnología obliga a recorrer al humanismo su tercera etapa ${ }^{10}$.

Esta coincidencia entre Lévi-Strauss y Rowe no es compartida universalmente en la historia de la etnología, e incluso un maestro de Caro Baroja

10 "Les trois humanismes", Demain, 35 (1956). Respuesta a una encuesta, que se incluye en pp. 319-322 de Antbropologie structurale deux. (Paris: Plon, 1973). Ha sido traducida en 1979 por Siglo XXI Eds., México. A falta del ejemplar, lo he retraducido yo. 
tan notable como el P. Wilhem Schmidt —cuya información sobre los estudios de los misioneros españoles manejó en su manual de 1949- tiene una opinión absolutamente negativa sobre el Renacimiento, que sólo puede explicarse por una cierta dosis de ese mismo fanatismo católico que el propio Lowie (1946: 235-236) perdona por la cosecha de datos obtenidos, de su parte y de su equipo. Sin embargo, en su historia comparada de las religiones constituyó realmente un obstáculo para comprender el proceso antropológico de conocimiento, incluso del religioso. Véase una muestra de su inquina al libre proceso de conocimiento producido en el Renacimiento: "Precisamente porque el Renacimiento colocó al paganismo clásico por encima de todo el mundo, sólo tarde llegó a cobrar interés por los pueblos y religiones dadas a conocer mediante los descubrimientos geográficos" ${ }^{11}$.

Quizá no sea necesario advertir al lector que los humanistas del Renacimiento eran cristianos y algunos, como Dante y Petrarca o Erasmo y Vives, eran incluso creyentes piadosos, que no colocaban obviamente las religiones paganas por encima de la cristiana. Por otro lado, debe decirse con claridad que es precisamente el efecto contrario lo que produce la estimación de la sociedad pagana de la Antigüedad, al permitir a los cristianos modernos comparaciones entre ellos y los nuevos pueblos. Por no alargarnos, tomemos solamente tres ejemplos notables del $s$. XVI y uno del xviII, todos ellos de personajes archiconocidos cuyo clasicismo contribuyó a la estima, tolerancia y mejor estudio de las religiones americanas.

En primer está el caso del franciscano Fr. Bernardino de Sahagún, que el propio Schmidt se ve obligado a reconocer como estudioso destacado de la religión mejicana: "hizo minuciosas indagaciones ante los sacerdotes y notables del antiguo Méjico acerca de toda la antigua religión mejicana, con sus fiestas, ritos, ofrendas y cantos, y que las transmitió en detallada exposición en la lengua original, ilustradas con figuras y dibujos" (1941: 42). Quizá le faltó decir que en este estudio de los mejicanos no se olvidó el fraile de tener en cuenta los métodos de estudio renacentistas, como prueba su interés por los "calepinos" (diccionarios plurilingües) lexicales europeos y por los modos retóricos del habla indígena, así como por sus sistemas de escritura jeroglífica: sobre que este trabajo se adecuaba a los gustos renacentistas no hay prueba mejor que el hecho de que la versión final se conserva en la biblioteca florentina de los Medici ${ }^{12}$.

11 Historia comparada de las religiones (Madrid, 1941, orig. 1930), p. 40.

12 Para un análisis reciente del humanismo de Sahagún, cf. Jesús Bustamante, «Retórica, traducción y responsabilidad histórica: claves humanísticas en la obra de 
Del dominico P. las Casas es bien conocido por don Julio y el público americanista su interés obsesivo por comparar las religiones de la Europa antigua con las indígenas de Méjico, Centroamérica y los Andes, de las cuales construyó una verdadera enciclopedia reivindicativa del honor americano, en su Apologética historia sumaria. De su carácter moderno dan constancia los análisis de sus diversos editores, tanto la de O'Gorman en el F.C.E. como la dirigida por Vidal Abril en Madrid (Alianza Ed., 1993). Muchos historiadores, y entre ellos el propio don Julio, lo han considerado un claro precedente de la obra conocida de Lafitau, Moeurs des sauvages américaines, comparés au moeurs des premiers temps (Paris, 1724), que por su sistemática comparación (religiosa, política, etc.) entre los antiguos griegos y americanos ha sido considerada obra fundacional de la etnología comparada ${ }^{13}$.

Por último, la obra de su antecesor jesuita José de Acosta sobre las sociedades de América y Asia es un ejemplo claro de la virtualidad del conocimiento clásico para la mejor comprensión de las religiones americanas. El propio don Julio usaba sus clasificaciones de las religiones americanas como prueba de su capacidad antropológica en varios capítulos de Las formas complejas de la vida religiosa (1978). Citaré solamente un texto su Historia natural y moral de las Indias (Sevilla, 1590), del prólogo y cap. 5 del libro $\mathrm{V}$, que creo suficiente para evidenciar su interés por las religiones americanas, lo contrario de lo que sugiere el temor del P. Schmidt:

Si alguno se maravillare de algunos ritos y costumbres de los indios [...] o los detestare por inhumanos y diabólicos, mire que en los griegos y romanos —que mandaron el mundo- se hallan o los mismos o semejantes, y a veces peores [...] No se contentó el demonio con hacer a los ciegos indios que adorasen el sol, y la luna y estrellas y tierra, y mar y cosas generales de naturaleza; pero pasó adelante a darles por dioses y sujetarlos a cosas menudas, y muchas de ellas soeces [...] Bien sabida cosa es el perro Osiris que adoraban los egipcios, y la vaca Isis y el carnero Amón; y en Roma la diosa Februa de las calenturas, y el Anser de Tarpeya; y en Atenas la sabia, el cuervo y el gallo...

No merece la pena seguir ofreciendo ejemplos de un análisis minucioso (que incluye formas y funciones religiosas perfectamente compren-

Bernardino de Sahagún", Berta ARES y OTROS, Humanismo y visión del otro en la España moderna (Madrid: C.S.I.C., 1992), pp. 245-375.

13 Cf. el capítulo de Anthony PAGDEN, en que se le considera como etapa final de la filosofía de Vitoria, Las Casas y Acosta: La caída del bombre natural. El indio americano y los orígenes de la Etnología comparativa (Madrid: Alianza Ed., 1986). En el mismo sentido elogioso, pero desde la posteridad ilustrada, cf. Michèle DucHET, Antropología e bistoria en el siglo de las Luces (Madrid: Siglo XXI, 1975). 
didas en las sociedades del Nuevo Mundo, por cotejo con las clásicas), sino simplemente mostrar de modo genérico que la comparación con el mundo clásico no inhibió el interés ni la capacidad de comprensión de las religiones diferentes, halladas por los europeos fuera de Europa. Y no se trata naturalmente de un fenómeno exclusivo del campo religioso, sino extendido al mundo lingüístico, filosófico, artístico o jurídico. Creo que el volumen de gramáticas y diccionarios surgidos de la mano de los misioneros eruditos, siguiendo el modelo latinista de Nebrija aplicado al castellano, sobra para satisfacer al más exigente. Baste decir que antes de la primera gramática inglesa de 1586 , ya se habían elaborado cuatro gramáticas americanas (tarasco, inca, nahuatl y zapoteco) en castellano ${ }^{14}$.

Pero no solamente cabe alabar a los eruditos humanistas por su interés por las lenguas no europeas - quizás en el fondo un tecnicismo útil a los fines pedagógicos y misionales- sino también por su estudio de la sabiduría popular misma, y ello "a partir de" la sabiduría clásica, no en contra: no es casual que la mayor parte de los autores dedicados a la recogida de refranes (Santillana, Juan de Valdés, el Comendador Griego, Laguna, Páez de Castro, Mal Lara, etc.) sean humanistas. No se trata de un fenómeno exclusivo del mundo castellano, sino también a nivel universal, como señaló tempranamente Menéndez y Pelayo en el discurso de contestación al ingreso de Rodríguez Marín en la Academia Española:

Grandes humanistas del siglo xvi, y Erasmo más que ninguno (1520), habían reconocido profundamente el valor de la sabiduría práctica contenida en los adagios y proverbios de los antiguos, y en torno de ellos había tejido el sabio de Rotterdam una especie de enciclopedia cuyo éxito superó al de todos sus libros. El triunfo de la Paremiología clásica bizo volver los ojos a la Paremiología vulgar, cuyo fondo era idéntico ${ }^{15}$ (subrayado mío).

A un nivel artístico incluso ha sido observado también este fenómeno por el profesor Erwin W. Palm, conocido especialista en arte indígena americano, cuando analizaba las ilustraciones que acompañaban a la colección de los Viaggi e navigazioni, editados por el célebre humanista italiano Juan Bautista Ramusio, traductor de tantas crónicas de Indias en las prensas venecianas. Ante el hecho de que tales ilustraciones (por ejemplo las que acompañan el texto de Jacquer Cartier sobre Montreal, que se parecen demasiado a las de otro viaje al Cuzco meridional, ofrecido en el mismo texto) evidentemente todavía no correspon-

\footnotetext{
14 J. H. ROWE, op. cit. (1974) (nota 8).

15 Madrid, 1907, p. 70.
} 
den a unos pintores viajeros - como los que acompañarán a Hernández a fines del XVI, o a las expediciones de Cook, Lapérouse o Malaspina a fines del XVIII - sino a modelos clásicos alejados de la realidad americana, no se le ocurre criticar su realismo sino adivinar su intención protoantropológica:

\begin{abstract}
El recinto cercado, abierto a un lado, naturalmente se encuentra como forma del típico poblado indígena desde las selvas de Brasil hasta los Grandes Lagos. Sin embargo, tantó las manzanas de casas cuidadosamente asentadas como la cruz griega en que está descrito el cuadrángulo central, saben a Renacimiento [...] El ilustrador del texto de Cartier, por lo tanto, proyecta una solución ideal de organización urbana sobre las tierras vírgenes de América [...] Hochelaga, en la forma como la presentó Ramusio a su audiencia humanista, no debe concebirse tanto como información etnológica desfigurada, sino como muestra de respeto hacia el indio, queriendo verlo como ser racional ${ }^{16}$ (subrayado mío).
\end{abstract}

Pero probablemente el campo en que más interese analizar la influencia del pensamiento clasicista, sobre la evolución de la capacidad observadora y clasificadora ante las otras culturas, sea el mundo del Derecho. Un proceso que no se reduce al siglo XVI, sino que persiste en el XVIII y sobre todo en el XIX, conectado a personajes y obras de clara identidad antropológica. No hace falta aludir a la conocida serie de abogados hispanos —educados en el programa renacentista de la Universidad española- que fueron capaces de ofrecer un informe propiamente etnográfico sobre la población indígena bajo su gobierno (Alonso de Zorita, García de Palacio, López Medel, Nicolás Matienzo, Licenciado Falcón, Vasco de Quiroga, Polo de Ondegardo, etc.), sino que bastaría mencionar solamente a los humanistas hispanos en Europa, capaces de un comentario jurídico sobre la propia legislación española según criterios romanos. Que no impidieron sino facilitaron la captación de los factores propios del ordenamiento hispano, tal como han sido estudiados por el profesor Tomás y Valiente en su conocido manual: Nebrija, Agustín, Covarrubias, Gregorio López, Palacios Rubio, Antonio Gómez, etc. El proceso intelectual que se da en este caso jurídico no se diferencia del que venimos analizando en párrafos anteriores con respecto a la religión, la lengua, la paremiología o la representación artística:

En el humanismo, en general, como corriente cultural amplísima, y en su concreta manifestación dentro del campo del pensamiento jurídico había gérmenes que

16 "La representación de la ciudad Precolombina en el siglo xVI. Realidad americana y concepto ideal", Boletín de la R. Acad. de Bellas Artes de S. Fernando, 49 (1979), pp. 129-131. 
debían conducir a actitudes filosófico-jurídicas progresivamente racionalistas [...] porque toda actitud humanista significa una fe admirativa en el hombre [...] Más en concreto: la historificación del Derecho romano contribuyó a la desmitificación [...] En efecto, al contemplar el Derecho romano no como un ordenamiento vigente en cualquier tiempo [ $=\mathrm{al}$ modo del Medievo, siguiendo el 'ius italicus' ] sino como el Derecho surgido en un tiempo y en un ámbito determinado, esto es como el Derecho de los romanos [=visión humanista], es claro que tal ordenamiento jurídico quede situado en la historia y, en cuanto tal, relativizado ${ }^{17}$.

Con estas alusiones nos queremos referir al efecto "desencadenante" de perspectiva cultural —urelativistam - que tiene el Derecho romano sobre los juristas que contemplan otros derechos. Este fenómeno clásico viene a ejercer en el Derecho el mismo papel desvelador que la admiración a los textos greco-latinos en el caso de los humanistas, que sufren en el momento de interpretarlos un proceso de "extrañamiento", que diría LéviStrauss. No estamos hablando de entelequias posibles sino de una realidad conocida por lo que hace al derecho castellano, en palabras de Tomás y Valiente, y de una realidad que se cumple regularmente en una serie de abogados ilustrados en Europa (Montesquieu, Turgot, Adam Smith, Lord Kames, John Millar, etc.) y sobre todo del s. XIX, en el cual puede decirse que los primeros antropólogos fueron de modo generalizado juristas ligados al Derecho romano: Maine, McLennan, Bachofen, Fustel de Coulanges, Frazer, etc. El hecho ha merecido ya un apartado especial en historias de la antropología como la de Ángel Palerm ${ }^{18}$. A este respecto, es curioso que don Julio se refiera en su manual de 1985 a dos de ellos (Bachofen y Frazer, pp. 69 y 83), señalando particularmente su carácter clasicista además de su formación jurídica, hacia la que no tenía la menor afición, al parecer. Efectivamente, cuando describe en Los Baroja sus amistades universitarias de los años 30 finales, señala claramente sus diferentes gustos bibliográficos:

Mis amigos viejos no se inclinaban a los asuntos sexuales [Marañón, etc.].. ni hablaban del "problema de España" [generación del 98]. Eran más bien aficionados a 'lo social', como se dice ahora, y tendían al marxismo. Leían por profesión libros de Derecho, que a mí no me atraían. Sólo muchos años más tarde he leído con gusto obras sobre el Derecho romano o el medieval. También tenían algunas lecturas antropológicas [...] (1972: 228) (subrayado mío).

17 Manual de historia del Derecho Español (Madrid: Tecnos, 1979), pp. 305-6.

18 Historia de la Etnología: los evolucionistas (México: Instituto Nacional de Antropología e Historia, 1976), que dedica el último apartado, el IV, a los «Juristas y etnólogos", donde incluye a los citados, junto con Morgan, Costa, Kovalevski y Lubbok, el famoso Lord Avebury. Este volumen ha sido reeditado junto con el primero, dedicado a los precursores, en la editorial española Alhambra, 1982. 
A este respecto, es posible que no hayamos recapacitado suficientemente sobre el peso clasicista soportado por la mayor parte de los abogados con interés antropológico de mediados del $\mathrm{xx}$, e incluso de comienzos. Son muy conocidas las figuras de la "Escuela histórica del Derecho" como la de F. C. Savigny, y su influencia sobre la escuela de abogados foralistas españoles (en particular, los catalanes al estilo de Durán y Bas, y el propio Joaquín Costa), pero no se aclara suficientemente que sus intereses foralistas o por el estudio de la cultura popular sólo se cumplieron a medias en la generación siguiente, es decir, en la de Wilhem Grim y Johan Bachofen, o en la de los jóvenes catalanes Maspons y Santamaría, o en el maduro Costa - a partir de 1879-. Porque lo que ellos eran realmente en principio se reducía a una posición crítica hacia el proceso codificador francés - de origen napoleónico-, y a una propuesta de relativización histórica, en base a sus conocimientos y comparaciones con el Derecho romano. El asunto merece un tratamiento aparte, que está todavía en preparación ${ }^{19}$. Sobre el interés no solamente jurídico sino ante todo clasicista de estos abogados fundadores de la antropología, como Maine, Bachofen o Fustel, ha insistido recientemente Arnaldo Momigliano ${ }^{20}$.

Pudiera parecer que el clasicismo y la antropología van juntos en el período contemporáneo solamente en el campo del Derecho, y no hay lugar ahora para ofrecer un panorama mejor. Pero quisiera, para compensar esta laguna hoy notable con una referencia del famoso texto histórico de Lowie (1937, 1946), señalar dos personajes que han salido fugazmente en nuestra historia, cuya producción peculiarmente antropológica se relaciona con su clasicismo. En primer lugar, se trata de Robert R. Marett -el sucesor de Tylor y antecesor de Radcliffe Brown, en la cátedra de antropología en Oxford-, cuya formación clasicista le habría permitido

19 Sobre Savigny y sus orígenes romanistas, puede consultarse el manual de Tomás y Valiente, antes citado. Aplicado a la escuela catalana, ha sido tratado reiteradamente por Luis Calvo y CALvo, a partir de su tesis doctoral. Cf. El «Arxiu d'Etnografia i Folklore de Catalunya y la Antropología Catalana (Barcelona: C.S.I.C., 1991). Por lo que respecta a Costa, ha insistido en esa visión Jesús DELGADO, "Costa y el Derecho", M. MATA CASTILlón, El legado de Costa (Zaragoza: Ministerio de Cultura y Diputación General de Aragón, 1984). Haré de ello el centro de atención de mi conferencia sobre Costa en el Congreso de Antropología, que se celebrará en Septiembre en Zaragoza, intentando reivindicar la contribución antropológica e historiográfica de los abogados romanistas. Costa derivó el derecho consuetudinario a partir del derecho romano, en que obtuvo un premio universitario en el homenaje al romanista Maranges.

20 Cf. la parte segunda de Tra storia e storicismo, titulada "Nuovi sentieri del Clasicismo nel XIX secolo", pp. 97-231 del citado libro (Pisa: Nistri-Lischi, 1985), que fue dada a conocer parcialmente en History and Theory, 21:4 (1982). La cita siguiente es de Robert H. LOWIE, Historia de la Etnologia (México: FCE, 1946). 
cuestionar el excesivo racionalismo intelectualista aplicado por sus antecesores al estudio de la religión —en particular, Tylor y Frazer-y, sobre todo, para su anticipo de un punto de vista funcionalista acerca del folklore, preguntándose sobre la razón de la persistencia actual de algunas supervivencias (Lowie, 1946: 137-8). Otra vez se produce el fenómeno paradójico de que un especialista en antigüedades es más consciente que los demás sobre el contraste del pasado con los fenómenos del tiempo presente, a los que dota así de historicidad y relativismo. Pero la referencia clasicista más importante en el texto de Lowie se relaciona con el héroe de su historia, Franz Boas, cuyas motivaciones más genuinamente funcionalistas y positivistas estarían ligadas, según él, al estímulo ofrecido por los estudios filológicos clasicistas:

\begin{abstract}
él fue quien elevó el trabajo de campo a un nivel enteramente nuevo, al insistir en que la técnica del etnógrafo debe estar a la altura de la del investigador de la civilización china, griega o islámica. Esto implica cierto conocimiento del idioma aborigen, para el cual ni el uso del pidgin English ni la traducción de un intérprete es substituto adecuado [...] Así vemos que la pasión que ostenta Boas por los textos en idiomas indígenas surge de la necesidad de contar con materiales que puedan, en cuanto a su valor documental, rivalizar con nuestras fuentes para el estudio de la Atenas de Tucídides o del renacimiento italiano. Las ipsisima verba de los indígenas representan datos primarios de la realidad cultural (1946: 163-4).
\end{abstract}

\title{
4. Algunas Pinceladas biográficas De DON JULIO Y SU Clasicismo.
}

A MODO DE EPÍLOGO

A modo de "exempla", anecdótica y entretenida como ellos, quisiera recoger de su autobiografía publicada alguna prueba del sólido basamento clasicista de su formación y primera profesionalización, así como del efecto persistente del mismo a lo largo de su vida y de sus gustos personales más intrascendentes, para mostrar de modo patente - al modo de los "ipsisima verba" del trabajo de campo- la íntima conexión de estos elementos con su manera de aprehender antropológicamente el mundo y las diversas sociedades, de que se ha ocupado como autor. Nos gustaría evidenciar así el papel de "extrañamiento" y perspectiva relativista proporcionada por el mismo, a pesar de que aparentemente se trata de un mundo propio -el mundo italiano del padre-, al que parece referirse conscientemente en su elección de sujeto antropológico. A recordar ahora el esquema kantiano de conocimiento antropológico, defendido por don Julio como su propia versión en 1985 , al inicio de su manual.

El uso de un material autobiográfico como haremos ahora tiene ventajas e inconvenientes, en cuanto que está mediado por la capacidad 
racionalizadora del autor. Parece un contrasentido contradecir la opinión disciplinar de un autor con sus propias confesiones, y eso se consideraría en la praxis antropológica una especie de traición «de lesa información. Pero las reiteraciones, contrasentidos y énfasis son tan "expresivos" como puedan serlo los sueños en un diván de psicoanalista. De otra parte, ciertos rasgos vitales y biográficos se repiten tanto que el autor difícilmente puede ocultarlos; así que nuestras pinceladas finales se ofrecen confiando en la sobreabundancia del material. Quede para otro momento una reflexión metodológica más profunda sobre los documentos autobiográficos, de tanta tradición en la historiografía antropológica a partir de los diarios de campo de Malinowski, y ello gracias a los recientes y jugosos aportes historiográficos del criticismo literario y del enfoque post-moderno.

En primerísimo lugar, lo clásico -en todas sus formas posibles- aparece en el texto de Los Baroja de una manera tan intensa que hay que no querer verlo para ignorarlo. Los clásicos salen a relucir entre sus estudios de secundaria, en sus lecturas personales universitarias y en la biblioteca de Itzea; en sus dudas de oposiciones y de congresos, en sus comparaciones de historia antigua o de antropología sobre los materiales de redacción; y finalmente en los propios personajes literarios -permítaseme llamar "personaje literario" a los que comparten el camino vital de don Julio, ya que el propio autor trata a los mismos como metáforas de personajes de Dickens o Marc Twain, especialmente en sus viajes al mundo anglosajón; pero también en sus viajes andaluces, en la descripción del Ateneo madrileño, etc.-. La única cátedra a que aspiró seriamente fue la de historia antigua de Salamanca, y ello puede servir también de rasgo que connota al personaje como un clasicista: también el único puesto realmente desempeñado "de oficio" en la Universidad fue el de ayudante de historia antigua, con Carmelo Viñas. Para ello había hecho la publicaciones sobre Los pueblos de España, siguiendo las huellas de Estrabón; para ello había traducido por su cuenta a Polibio o Jenofonte, o acaparaba ediciones cuidadas de estos autores. Es sumamente reveladora la confesión de su encuentro privilegiado con el griego en secundaria:

En la clase de griego tradujimos o intentamos traducir la "Apología de Sócrates". Los alumnos más dispuestos llegaban a entender correctamente y a analizar bien. Pero creo que el único que se conmovió algo por el contenido fui yo. Esto me enorgullecerá siempre (1972: 167).

No solamente llegó a ser un estudiante aventajado y joven profesor de historia antigua, sino especialmente interesado en el mundo clásico. Es verdad que se interesaba más en el pasado que en el presente, en 
materias y enfoques intelectuales, pero además lo hacía como una elección personal, como una conversión íntima:

\begin{abstract}
Mientras mis condiscípulos pensaban en la metáfora y la alusión, yo pensaba en los orígenes del culto dionisíaco, en las divinidades ctónicas y en el culto a los héroes [...] No creo que admití ningún sistema de los clásicos, desde los de Max Muller al del padre Schmidt, pero salí de aquella aventura con una simpatía acentuada por el politeísmo como sistema y por el paganismo como práctica (1972: 230).
\end{abstract}

Más que profesor o estudioso de historia antigua, era realmente un clasicista, un hombre que asumía un modelo de vida, al modo renacentista. Véase la prueba: "Con la historia antigua de Oriente me estrellaba. Ni los egipcios, ni los sumerios, babilonios, asirios, hititas, etcetera, me producían atracción. Era puramente clásico en mis gustos" (1972: 341)

Ahora bien, no sería justo decir que don Julio permaneció con estos mismos gustos siempre, y con las mismas prácticas de lectura. Y esta es la parte más interesante de su clasicismo "extrañador", despertador de su conciencia antropológica. El joven cambia de gusto, pero ya de mayor reconoce el peso de lo clásico en la elección posterior:

Desde la época en que iba de adolescente al Museo de Reproducciones hasta pasada la juventud, me gustó mucho la escultura griega [...] A través de Praxiteles, etc. descubrí la posibilidad de belleza del cuerpo humano [...] me dieron un ideal de perfección en la forma, que ahora ya no tengo porque prefiero una virgen gótica en alabastro o una tabla sencilla [...] El gusto por lo arqueológico me hizo profundizar en el análisis y evolución de las formas (1972: 341).

Creo que esta sensibilidad y gusto por las formas fue más allá, hasta la adopción de todo un sistema interpretativo, y de reconocimiento de formas antiguas en las nuevas, de reconocimiento de supervivencias (al estilo de Marett, con consciencia de las nuevas funciones, o mezclas con el presente). Hay todo un mundo en su autobiografía para medir hasta dónde llega su clasicismo en la percepción de los fenómenos en el campo: a este respecto, su visita a Andalucía con Foster le dio ocasión de considerar la cantidad de elementos romanos que persistían: en las formas de vida laboral de un campesino andaluz dentro de un cortijo, cercanas a la esclavitud romana (1972: 455); en el seno de la vida política franquista representada, por los dicterios del cardenal Segura, como "guardia pretoriana" que pone y depone emperadores (i.e., reyes borbones) (1972: 458-9); de la tecnología huertana en Murcia, "que podría servir como introductorio a un curso de mecánica helenística o arábiga" (1972: 463); y sobre todo, el episodio bellísimo de la Semana Santa en Puente Genil, de Córdoba, a cabalo entre las borracheras de los romanos y la "sensualidad del culto" de las 
jóvenes andaluzas, estrenando sus vestidos y sus cuerpos en crecimiento ante la mirada extasiada del sexo contrario (1972: 470-1). El propio viaje a Estados Unidos le da ocasión de poner a prueba sus recuerdos helenísticos e italianos, y le parece observar a antiguos contertulios en arqueología clásica entre los limpiabotas de Otumwa, la villa natal de Foster (1972: 495), y al mismísimo Ulises en persona en la figura de un compañero de avión italiano que regresaba, como él y con él, al hogar (1972: 497).

De esta manera, yo creo que el bautizo clasicista ha ejercicido en don Julio no solamente como hilo conductor de su proceso formativo, de sus conocimientos, sus esquemas y sus gustos profesionales y poéticos, sino también como modo de trascender su propio etnocentrismo hispano. Sus primeros estudios sobre el pueblo vasco y sobre Vera de Bidasoa no estuvieron tan lejos de Estrabón como pudiera pensarse, y de hecho su monografía de 1946 sobre Los pueblos de España, se hizo "como una glosa a las observaciones de Estrabón y otros autores clásicos respecto del matriarcado de los cántabros en el período prerromano" ${ }^{21}$. Pero el propio autor describe sus primeros trabajos de campo en su pueblo de Vera durante la guerra civil como un esfuerzo compartido con miles de lecturas, consumidas vorazmente y en soledad hacia una búsqueda de sí mismo en el pasado, y compartido con conservaciones intermitentes aldeanas:

En lo único que pude trabajar con cierto desarrollo de sociabilidad fue en mis estudios vascos, aunque tampoco la época era muy buena que digamos para su desenvolvimiento [...] Pude realizar alguna investigación de campo hablando con mis vecinos [...] y fui haciendo apuntes (1972: 346).

Pero, ese aparente estudio endógeno —empezando por sí mismo, es decir, desde el propio mundo vasco- fue posible gracias a las lejanas y pretéritas inquietudes por la etnohistoria romana, contrastada en el presente con encuestas y contactos personales. Sobre la dificultad de estos contactos, retomamos muchas páginas más adelante el pulso para enterarnos de las dificultades que tuvo que superar en sus encuestas vascas. Nada que ver con las facilidades ofrecidas en otra tierra lejana, la andaluza, descubierta "en su salsa" gracias a la oferta de colaboración académica de un colega norteamericano. Me gustaría concluir este rosario de citas autobiográficas con una confesión surgida ante el éxito de sus encuestas andaluzas, y ante una informante muy curiosa, que contradice del todo el postulado folklórico de que son los indígenas autóctonos quienes más saben y más se interesan por lo propio:

21 Antonio Carreira, Julio Caro Baroja, etnógrafo (Universidad de Cantabria: Aula de Etnografía, 1995), p. 7. 
Aquí [en El Alosno, en la sierra del Andévalo de Huelva] tuvimos la suerte de establecer relación con un joven, Manuel Lisardo Bowie, con su madre y su hermana. No puede imaginarse familia andaluza más típica. Sin embargo, la madre, ya anciana, doña Margarita Bowie, era hija de escocés: de un empleado de la mina próxima [Río Tinto]. No he conocido en mi vida mujer más despierta para responder a un cuestionario folklórico y que supiera más de tales usos, creencias y costumbres de la tierra. Era una especie de doña Cecilia Böhl de Faber en potencia, y a mí lo que me hacía reflexionar más, precisamente, era la similitud de las dos en ser hijas de nórdicos y en tener conciencia andaluza tan extrema$d a[. .$.$] Me chocaba esto, también, pensando en mi caso propio, pues yo he teni-$ do mucha curiosidad por los países respectivos de antepasados mucho más lejanos [...] me dictó hasta 113 fórmulas de medicina popular, de creencias y usos [...] así como con el calendario festivo [...] en Vera, siendo vecino de un mismo barrio casi desde que nací, me costaba Dios y ayuda sonsacar algo a éste o a aquél [...] y no faltaba quien contestaba con un pregunta... (1972: 460-1).

Creo que esta confesión, y esta comparación de informantes, resulta altamente significativa a la hora de decidir el origen endógeno o exógeno -kantiano y socrático, o más bien exótico y de retorno- del conocimiento antropológico. Pareciera que a los informantes les hubiera sido más fácil la procedencia lejana, para suscitarles la curiosidad y el interés por la cultura en que vivían. Al propio autor, embutido de lecturas y perspectivas clásicas, fueron éstas las que le proporcionaron la necesaria y previa perspectiva de lejanía. El mundo mediterráneo, y en particular el italiano al que el autor quería volver en su vejez con más frecuencia de lo que lo hizo, le servía de brújula en su viaje etnográfico por el mundo propio.

El ejemplo de don Julio, tanto en sus lecturas personales y escritos publicados como en su propias confesiones autobiográficas es, en suma, un microcosmo de la historia disciplinar. Lo clásico ha sido interpretado por el autor como ejemplo del mundo cultural propio, y no cabe duda que - por comparación con el americano o el del Cercano Oriente- lo es: pero por comparación con el mundo vasco, madrileño o andaluz ciertamente que no, y posiblemente es lo que ha permitido esa mirada lejana y curiosa en que parece residir gran parte del estilo antropológico.

FERMÍN DEL PINO DÍAZ

Departamento de Antropología Instituto de Filología. CSIC 
Se presenta la tesis del origen renacentista de la antropología (Rowe, 1965), de acuerdo a la definición de ésta como reconocimiento legítimo de las diferencias entre las sociedades, hecho posible por la idealización renacentista de las sociedades clásicas y la autocrítica de su propio etnocentrismo. Se analizan luego las consecuencias de esta hipótesis dentro de la historia antropológica en la Edad Moderna y Contemporánea, y se aplica al caso de Julio Caro Baroja como si fuera un "microcosmos" de la historia antropológica general por su educación como historiador del mundo antiguo y su autodefinición como historiador y antropólogo.

In his 1965 article on the Renaissance foundations of anthropology, John Rowe defined the discipline as, basically, the legitimate identification of differences among societies, and posited that anthropology emerged when scholars of the Renaissance idealized the societies of Antiquity and criticized their own ethnocentrism. By analyzing the implications of the argumen in the history of the discipline in the 16th through the 20th centuries, the autor maintains that Julio Caro Baroja's career epitomizes that history, partly beacause of his education as an historian of Antiquity and because os his self-definition as both a historian and an anthroplogist. 